\title{
Sinus heart rate post pulmonary vein ablation and long-term risk of recurrences
}

\author{
Gesa von Olshausen ${ }^{1}$ (I) - Ott Saluveer ${ }^{1} \cdot$ Jonas Schwieler $^{1} \cdot$ Nikola Drca $^{1} \cdot$ Hamid Bastani $^{1} \cdot$ Jari Tapanainen $^{1}$. \\ Tara Bourke ${ }^{1}$. Astrid Paul-Nordin ${ }^{1}$. Göran Kennebäck ${ }^{1}$. Per Insulander ${ }^{1}$ - Mats Jensen-Urstad ${ }^{1}$. \\ Frieder Braunschweig ${ }^{1}$
}

Received: 19 May 2020 / Accepted: 15 October 2020 / Published online: 12 November 2020

(c) The Author(s) 2020

\begin{abstract}
Purpose Cather ablation is known to influence the autonomic nervous system. This study sought to investigate the association of sinus heart rate pre-/post-ablation and recurrences in patients with atrial fibrillation undergoing pulmonary vein isolation (PVI).

Methods Between January 2012 and December 2017, data of 482 patients undergoing their first PVI were included. Sinus heart rate was recorded before (PRE), directly post-ablation (POST) and 3 months post-ablation ( $3 \mathrm{M})$. All patients were screened for atrial tachyarrhythmia recurrences during the one-year follow-up.

Results In the total study cohort, the mean resting sinus heart rate at PRE [mean $57.9 \mathrm{bpm}$ (95\% CI 57.1-58.7 bpm)] increased by over $10 \mathrm{bpm}$ to POST [mean $69.4 \mathrm{bpm}(95 \%$ CI $68.5-70.3 \mathrm{bpm}) ; p<0.001$ ] followed by a slight decrease at $3 \mathrm{M}$ [mean $67.3 \mathrm{bpm}$ (95\% CI 66.4-68.2 bpm)] but still remaining higher compared to PRE $(p<0.001)$. This pattern was observed in patients with and without recurrences at POST and $3 \mathrm{M}$ (both $p<0.001$ compared to PRE). However, at $3 \mathrm{M}$ the mean sinus heart rate was significantly lower in patients with compared to patients without recurrences $(p=0.031)$. In this regard, patients with a heart rate change $<11 \mathrm{bpm}$ (PRE to $3 \mathrm{M}$ ) or, as an alternative parameter, patients with a heart rate $<60 \mathrm{bpm}$ at $3 \mathrm{M}$ had a significantly higher risk of recurrences compared to the remaining patients (Hazard ratio (HR) 1.82 (95\% CI 1.32-2.49), $p<0.001$ and HR 1.64 (95\% CI 1.20-2.25), $p=0.002$, respectively).

Conclusion Our study confirms the impact of PVI on cardiac autonomic function with a significant sinus heart rate increase post-ablation. Patients with a sinus heart rate change $<11 \mathrm{bpm}$ (PRE to $3 \mathrm{M}$ ) are at higher risk for recurrences during oneyear post-PVI.
\end{abstract}

Keywords Atrial fibrillation $\cdot$ Pulmonary vein isolation $\cdot$ Parasympathetic denervation $\cdot$ Sinus heart rate $\cdot$ Recurrence

\section{Introduction}

Atrial fibrillation is the most common arrhythmia of clinical significance and its prevalence is rising worldwide [1]. Catheter ablation aiming at pulmonary vein isolation (PVI) has

Gesa von Olshausen and Ott Saluveer contributed equally.

Electronic supplementary material The online version of this article (https://doi.org/10.1007/s00392-020-01765-z) contains supplementary material, which is available to authorized users.

Gesa von Olshausen

gesa.von.olshausen@ki.se

1 Department of Cardiology, Karolinska University Hospital, S1:02, 17176 Solna, Stockholm, Sweden become an effective treatment option in patients with symptomatic atrial fibrillation. However, recurrences of atrial tachyarrhythmias after initially successful catheter ablation are common and often require re-do ablations [2]. Despite increasing knowledge about the risk factors for recurrences, identifying patients at risk for recurrence that would benefit from close monitoring remains challenging. The autonomic nervous system has been shown to play a pivotal role in the pathogenesis of atrial fibrillation [3]. In this regard, it has been shown that patients with atrial fibrillation and a low resting sinus heart rate prior to ablation seem to carry a higher risk for recurrence of atrial fibrillation post-ablation $[4,5]$. It has been suggested that catheter ablation has an attenuating effect on parasympathetic activity $[6,7]$ leading to an increased resting heart rate post-ablation. In this 
context, it has been shown that a low sinus heart rate postablation is associated with a significantly higher recurrence risk of atrial fibrillation during follow-up [8-10]. However, studies were either limited by sample size or timepoints for significant changes in sinus heart rate differed. Hence, the aim of this study was to investigate the association of sinus heart rate pre-/post-ablation and recurrences in patients undergoing PVI for atrial fibrillation in a large cohort.

\section{Methods}

\section{Study population}

All patients who underwent catheter ablation for atrial fibrillation at the Karolinska University Hospital between January 2012 and December 2017 were included provided that a first-time PVI procedure using the radiofrequency technique was performed without major complications such as cardiac tamponade, cerebrovascular events, major bleeding and $\mathrm{AV}$ fistula. Patients subjected to additional ablation lines in the right/left atrium or ablation of complex fractionated atrial electrograms were excluded. Patients with a pacemaker or implantable cardioverter defibrillator were also excluded. Complete follow-up information had to be available for 12 months post-PVI. Relevant patient characteristics and procedural details were prospectively collected at the time of the ablation procedure and recorded in a computerized database. All patient data and follow-up information were derived from the digital medical record system (TakeCare, CompuGroup Medical Sweden, Uppsala, Sweden) which covers most of the hospitals and medical practices in Stockholm county.

According to the 2016 ESC guidelines for the management of atrial fibrillation [11], atrial fibrillation was classified as paroxysmal if self-terminating (in most cases within $48 \mathrm{~h}$ ) or if atrial fibrillation episodes were cardioverted within 7 days. Atrial fibrillation was classified as persistent if it lasted longer than 7 days, including episodes that were terminated by cardioversion (either with drugs or by direct current cardioversion) after 7 days or more.

\section{Catheter ablation procedure}

Oral anticoagulation therapy was prescribed at least one month before the procedure. Transesophageal echocardiography prior to the procedure was performed to exclude left atrial appendage thrombus in all patients. The ablation procedures were performed under conscious sedation and analgesia. Throughout the procedure, a continuous infusion of heparin was maintained to achieve an activated clotting time (ACT) of $>300 \mathrm{~s}$ and ACT measurements were routinely done every $30 \mathrm{~min}$. All patients underwent sole circumferential PVI as described before at our institution [12]. In brief, vascular access was obtained using the right and/or left femoral vein. Under fluoroscopic guidance transseptal access to the left atrium was established through which the radiofrequency ablation catheter (Biosense-Webster Inc., Diamond Bar, CA, USA) and circular mapping catheter (Lasso, Biosense-Webster Inc., Diamond Bar, CA, USA) guided by a 3-dimensional mapping system (Carto, Biosense-Webster Inc., Diamond Bar, CA, USA or NavX, St. Jude Medical Inc., St. Paul, MN, USA) were advanced into the left atrium. Circumferential lesions were created to surround the right and left pulmonary veins (PV) with a $3.5 \mathrm{~mm}$ irrigated-tip catheter (Biosense-Webster Inc., Diamond Bar, CA, USA). RF energy was applied with a power between 25 and $35 \mathrm{~W}$, with an irrigation rate of 10 to $40 \mathrm{~mL} / \mathrm{min}$.

Acute procedural success was defined as an entrance and exit block at least 20 min after initial PV isolation, documented with a circular mapping catheter. Those PVs with acute reconnection were re-isolated. Application of adenosine to assess for dormant PV conduction after ablation was not performed. All patients who underwent ablation were treated with the same approach.

\section{Post-ablation follow-up}

Post-ablation, patients were closely monitored for post-procedural complications and discharged home after $24 \mathrm{~h}$. Oral anticoagulation was continued for at least 3 months postablation. Further use of oral anticoagulation was determined according to the ESC guidelines [11]. At the discretion of the treating physician, prescription of anti-arrhythmic drugs (AADs) during the 3 months blanking period was performed to favor reverse electrical and structural atrial remodelling. AADs were stopped in all symptom-free patients not later than the end of the blanking period.

For heart rate assessment, resting 12-lead electrocardiograms (ECGs) were recorded within $24 \mathrm{~h}$ before ablation (PRE), within $24 \mathrm{~h}$ post-ablation (POST) and 3 months post-ablation (3 M). Patients were only included when sinus rhythm was present during these ECG measurements.

For ECG registration, patients had to lay down in supine position. After 3-5 min of rest, the ECG was recorded. ECG registration was at a paper speed of $50 \mathrm{~mm} / \mathrm{s}$ (PHILIPS, Amsterdam, Netherlands) and digitally stored in the digital medical record system.

Patients were followed-up for one year with clinical visits in the outpatient clinic and at medical practices scheduled at 3-, 6- and 12-months post-procedure. An ambulatory ECG and/or 24-h Holter ECG (at least one Holter ECG during follow-up) was routinely obtained during follow-up visits as well as during unscheduled ambulatory visits related to arrhythmia recurrences. Documentation of arrhythmic episodes was based on ECG, Holter-ECG or event loop recorder 
(when available). Recurrences were defined as any documented atrial tachyarrhythmia (atrial fibrillation, atrial flutter, atrial tachycardia) lasting $>30 \mathrm{sec}$ occurring after the 3 months blanking period.

\section{Statistical analysis}

Continuous variables are presented as mean \pm standard deviation or $95 \%$ confidence intervals and were compared using Student's t-tests and ANOVAs. Continuous variables presented as median and interquartile range were compared using Mann-Whitney tests. Categorical variables are expressed as frequencies/percentages and were compared by Chi-square tests. The Kaplan-Meier method was used for building event curves. Hazard ratios with $95 \%$ confidence intervals and $p$ values from Cox regression and Log-Rank analyses are provided. All statistical tests and confidence intervals were 2-sided, with a significance level of 0.05 . Univariate and multivariable backward logistic regression analyses were performed. The multivariable model considered factors associated with a $p$ value $<0.05$ in univariate analysis. Log-rank optimization was performed to determine a cutoff which may have prognostic significance for recurrence. The optimal cut-off was considered as the sinus heart rate change (from PRE to $3 \mathrm{M}$ ) separating the population in two groups of which the log-rank comparison revealed the highest chi-square statistic. This was performed using the $\mathrm{R}$ package 'maxstat' Version 0.7-25 in R (Version 3.6.1) [13]. All other statistical analyses were performed using SPSS software, version 25 (IBM Corp., Armonk, New York).

\section{Results}

Between January 2012 and December 2017, 1836 patients underwent ablation for atrial fibrillation at the Karolinska University Hospital. From this patient cohort, 482 patients fulfilled the inclusion criteria and were included in the analysis (Figure 1, supplementary). Patients were divided into two groups dependent on experiencing recurrences [173 patients (35.9\%)] vs. no recurrences [309 patients (64.1\%)]. Patients with recurrences compared to patients without recurrences had a significantly higher body mass index (27.4 vs. $26.4 \mathrm{~kg} / \mathrm{m} 2, p=0.002$ ), more persistent than paroxysmal atrial fibrillation $(46.8 \%$ vs. $15.5 \%, p<0.001)$, a longer history of atrial fibrillation (5.0 vs. 4.0 years, $p<0.001)$, a higher $\mathrm{CHA}_{2} \mathrm{DS}_{2}$-VASc Score $(p=0.033)$, more arterial hypertension $(53.2 \%$ vs. $38.8 \%, p=0.003)$, more diabetes mellitus $(9.2 \%$ vs. $4.2 \%, p=0.029)$, a larger left atrial size in the parasternal long axis ( 39.9 vs. $38.9 \mathrm{~mm}, p=0.012$ ), received more beta-blocker at PRE $(69.4 \%$ vs. $60.2 \%$, $p=0.049)$ as well as at $3 \mathrm{M}(71.1 \%$ vs. $57.9 \%, p=0.004)$ and received more other AADs at $3 \mathrm{M}(p=0.047)$. All baseline and procedural characteristics of patients with and without recurrences are presented in Table 1.

The mean resting sinus heart rate of the total study population was 57.9 beats per minute (bpm) before ablation (PRE) (95\% CI 57.1-58.7 bpm). Directly post-ablation (POST) it significantly increased by $11.5 \mathrm{bpm}$ (mean 69.4 bpm (95\% CI 68.5-70.3 bpm); $p<0.001$ ) (Fig. 1a) with a distribution of heart rate change (PRE to POST) as provided in Fig. 2, supplementary. After 3 months post-ablation ( $3 \mathrm{M})$, the heart rate slightly decreased but remained markedly higher as compared to PRE (mean $67.3 \mathrm{bpm}$ (95\% CI 66.4-68.2 bpm); $p<0.001$ ) (Fig. 1a) with a distribution of heart rate change (PRE to $3 \mathrm{M}$ ) as provided in Figure 2, supplementary. This increasing pattern was observed in patients with as well as without recurrences at POST and $3 \mathrm{M}$ respectively (both $p<0.001$ as compared to PRE). However, in patients with recurrences the mean heart rate was significantly lower compared to patients with no recurrences at $3 \mathrm{M}$ (mean $66.0 \mathrm{bpm}(64.4-67.6 \mathrm{bpm})$ vs. mean $68.1 \mathrm{bpm}$ (95\% CI 67.0-69.2 bpm); $p=0.031$ ) (Fig. 1b). Due to this difference at $3 \mathrm{M}$, we analyzed the heart rate change (PRE to $3 \mathrm{M}$ ) and the corresponding probability of recurrence. In this analysis, an increase of sinus heart rate change went along with a decreased probability of recurrence (Hazard ratio (HR) 0.85 (95\% CI 0.78-0.94); $p=0.001$ ) (Fig. 2). In addition, we performed a Log-Rank optimization to determine a cut-off of heart rate change (PRE to $3 \mathrm{M}$ ) which maximized the discrimination for recurrences. This analysis revealed a cut-off of $11 \mathrm{bpm}$. According to this cut-off, 266 patients $(55.2 \%)$ had a heart rate change $<11 \mathrm{bpm}$ and 216 patients $(44.8 \%)>=11 \mathrm{bpm}$. Treatments with beta-blocker and other antiarrhythmic drugs (AADs) as well as procedural characteristics were similar in both groups (Table 2). Recurrences occurred in 115 patients $(43.2 \%)$ in the heart rate change $<11 \mathrm{bpm}$ group compared to 58 patients (26.9\%) in the heart rate change $>=11 \mathrm{bpm}$ group (HR 1.82 (95\% CI 1.32-2.49), $p<0.001$ ) during a one-year follow-up. The corresponding Kaplan-Meier-curve is provided in Fig. 3. In multivariable analysis, a heart rate change $<11 \mathrm{bpm}$ (PRE to $3 \mathrm{M})$ remained independently associated with recurrences (Table 1, supplementary).

For further analysis, we divided all patients into quartiles regarding to their sinus heart rate at $3 \mathrm{M}$. Patients in the 1 st quartile had a significantly increased risk of recurrences compared to the 4th quartile (HR 1.59, 95\% CI $1.05-2.38, p=0.027$ ) while the other quartiles showed a comparable recurrence risk (2nd quartile HR 1.02, 95\% CI $0.66-1.58, p=0.938$ and 3rd quartile HR 0.88 , 95\% CI 0.56-1.39, $p=0.588$ ) during a one-year followup (Table 3; corresponding Kaplan-Meier curve Figure 3, supplementary). In a direct comparison, patients in the 1st quartile had a significantly higher risk of recurrences compared to patients in the 2 nd- 4 th quartile (57 
Table 1 Baseline and procedural characteristics of patients with and without recurrences

\begin{tabular}{|c|c|c|c|c|}
\hline Baseline characteristics & All patients $(n=482)$ & No recurrence $(n=309)$ & Recurrence $(n=173)$ & $p$ value \\
\hline Age (years) & $59.3 \pm 10.1$ & $59.1 \pm 10.3$ & $59.5 \pm 9.8$ & 0.650 \\
\hline Male, $n(\%)$ & $319(66.2)$ & $214(69.3)$ & $105(60.7)$ & 0.071 \\
\hline BMI $(\mathrm{kg} / \mathrm{m} 2)$ & $26.8 \pm 3.5$ & $26.4 \pm 3.4$ & $27.4 \pm 3.6$ & 0.002 \\
\hline Type of atrial fibrillation & & & & $<0.001$ \\
\hline Paroxysmal, $n(\%)$ & $353(73.2)$ & $261(84.5)$ & $92(53.2)$ & \\
\hline Persistent, $n(\%)$ & $129(26.8)$ & $48(15.5)$ & $81(46.8)$ & \\
\hline Duration of atrial fibrillation in the past, years & $4.2(2.0 ; 7.3)$ & $4.0(2.1 ; 6.0)$ & $5.0(2.9 ; 10.0)$ & $<0.001$ \\
\hline Number of failed AADs & $1.1 \pm 0.7$ & $0.9 \pm 0.6$ & $1.3 \pm 0.8$ & $<0.001$ \\
\hline $\mathrm{CHA}_{2} \mathrm{DS}_{2}$-VASc Score, $n(\%)$ & & & & 0.033 \\
\hline 0 & $133(27.6)$ & $89(28.8)$ & $44(25.4)$ & \\
\hline 1 & $158(32.8)$ & $112(36.2)$ & $46(26.6)$ & \\
\hline 2 & $108(22.4)$ & $59(19.1)$ & $49(28.3)$ & \\
\hline$>=3$ & $83(17.2)$ & $49(15.9)$ & $34(19.7)$ & \\
\hline Congestive heart failure, $n(\%)$ & $32(6.6)$ & $19(6.1)$ & $13(7.5)$ & 0.571 \\
\hline Structural heart disease & & & & 0.792 \\
\hline Ischemic cardiomyopathy, $n(\%)$ & $15(3.1)$ & $11(3.6)$ & $4(2.3)$ & \\
\hline Dilated cardiomyopathy, $n(\%)$ & $8(1.7)$ & $6(1.9)$ & $2(1.2)$ & \\
\hline Hypertrophic cardiomyopathy, $n(\%)$ & $6(1.2)$ & $4(1.3)$ & $2(1.2)$ & \\
\hline Arterial hypertension, $n(\%)$ & $212(44.0)$ & $120(38.8)$ & $92(53.2)$ & 0.003 \\
\hline Diabetes mellitus, $n(\%)$ & $29(6.0)$ & $13(4.2)$ & $16(9.2)$ & 0.029 \\
\hline Hyperlipidemia, $n(\%)$ & $80(16.6)$ & $50(16.2)$ & $30(17.3)$ & 0.799 \\
\hline Left atrial size, parasternal long axis (mm) & $39.3 \pm 4.3$ & $38.9 \pm 4.1$ & $39.9 \pm 4.6$ & 0.012 \\
\hline Left ventricular ejection fraction (\%) & $58.1 \pm 4.5$ & $58.4 \pm 4.4$ & $57.7 \pm 4.6$ & 0.108 \\
\hline Time of RF energy delivery (sec) & $2677.0 \pm 946.8$ & $2642.5 \pm 891.6$ & $2736.1 \pm 1038.3$ & 0.354 \\
\hline Procedure time (min) & $172.2 \pm 50.5$ & $167.4 \pm 47.5$ & $179.5 \pm 54.7$ & 0.009 \\
\hline Fluoroscopy time (min) & $15.6 \pm 9.6$ & $15.1 \pm 9.5$ & $16.4 \pm 9.5$ & 0.096 \\
\hline Beta-blocker at PRE, $n(\%)$ & $306(63.5)$ & $186(60.2)$ & $120(69.4)$ & 0.049 \\
\hline Other AADs at PRE & & & & 0.871 \\
\hline Dronedarone, $n(\%)$ & $60(12.4)$ & $37(12.0)$ & $23(13.3)$ & \\
\hline Flecainid, $n(\%)$ & $56(11.6)$ & $33(10.7)$ & $23(13.3)$ & \\
\hline Sotalol, $n(\%)$ & $43(8.9)$ & $29(9.4)$ & $14(8.1)$ & \\
\hline Amiodarone, $n(\%)$ & $24(5.0)$ & $16(5.2)$ & $8(4.6)$ & \\
\hline Disopyramid, $n(\%)$ & $8(1.7)$ & $4(1.3)$ & $4(2.3)$ & \\
\hline Propafenon, $n(\%)$ & $1(0.2)$ & $1(0.3)$ & $0(0.0)$ & \\
\hline Beta-blocker at $3 \mathrm{M}, n(\%)$ & $302(62.7)$ & $179(57.9)$ & $123(71.1)$ & 0.004 \\
\hline Other AADs at $3 \mathrm{M}$ & & & & 0.047 \\
\hline Dronedarone, $n(\%)$ & $27(5.6)$ & $13(4.2)$ & $14(18.1)$ & \\
\hline Flecainid, $n(\%)$ & $19(3.9)$ & $7(2.3)$ & $12(6.9)$ & \\
\hline Sotalol, $n(\%)$ & $21(4.4)$ & $12(3.9)$ & $9(5.2)$ & \\
\hline Amiodarone, $n(\%)$ & $13(2.7)$ & $8(2.6)$ & $5(2.9)$ & \\
\hline Disopyramid, $n(\%)$ & $2(0.4)$ & $1(0.3)$ & $1(0.6)$ & \\
\hline Propafenon, $n(\%)$ & $0(0.0)$ & $0(0.0)$ & $0(0.0)$ & \\
\hline
\end{tabular}

$B M I$ body mass index, $A A D$ antiarrhythmic drug, $R F$ radiofrequency

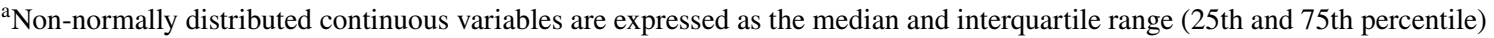

patients (47.1\%) vs. 116 patients (32.1\%); HR $1.64(95 \%$ CI 1.20-2.25), $p=0.002$ ) (Fig. 4). Treatments with betablocker and other AADs as well as procedural characteristics were similar in patients of the 1st quartile compared to patients in the 2 nd -4 th quartile (Table 4$)$. In multivariable analysis, a heart rate $<60 \mathrm{bpm}$ at $3 \mathrm{M}$ remained independently associated with recurrences (Table 2 , supplementary). 
A

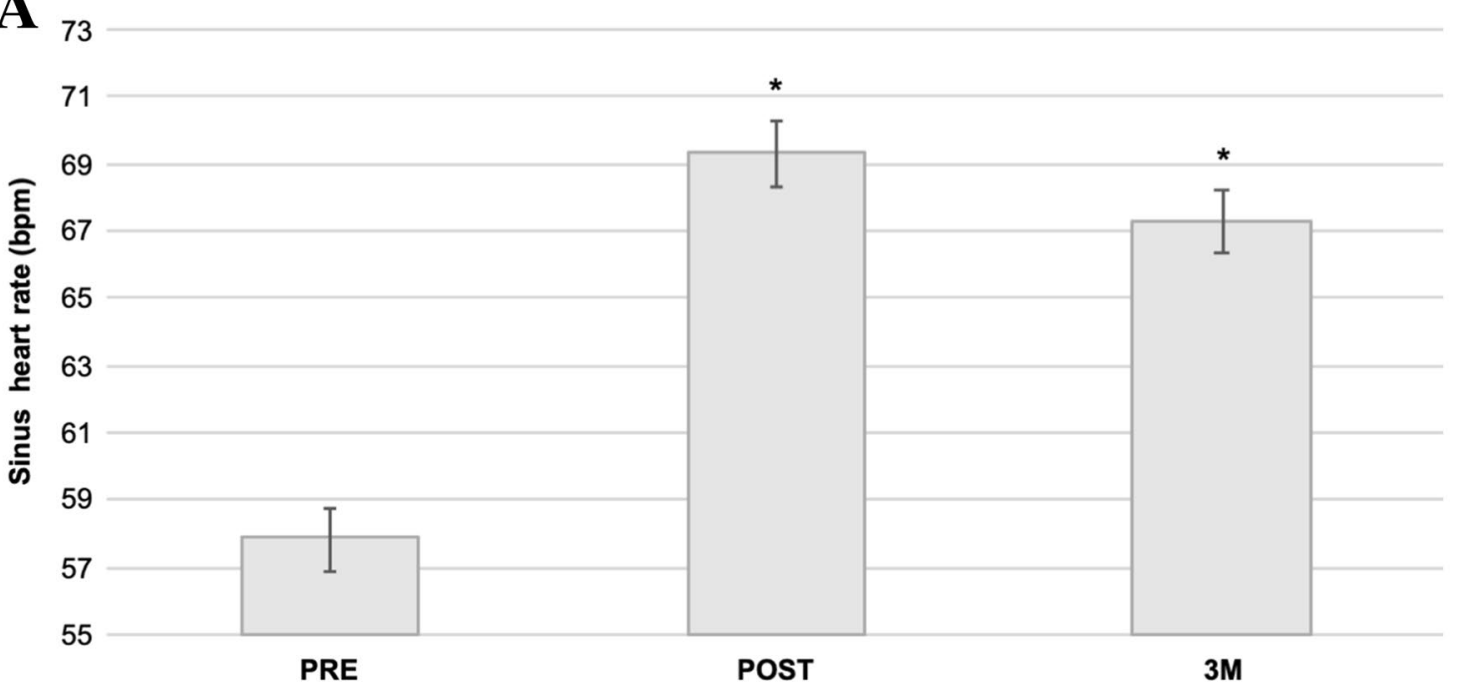

B

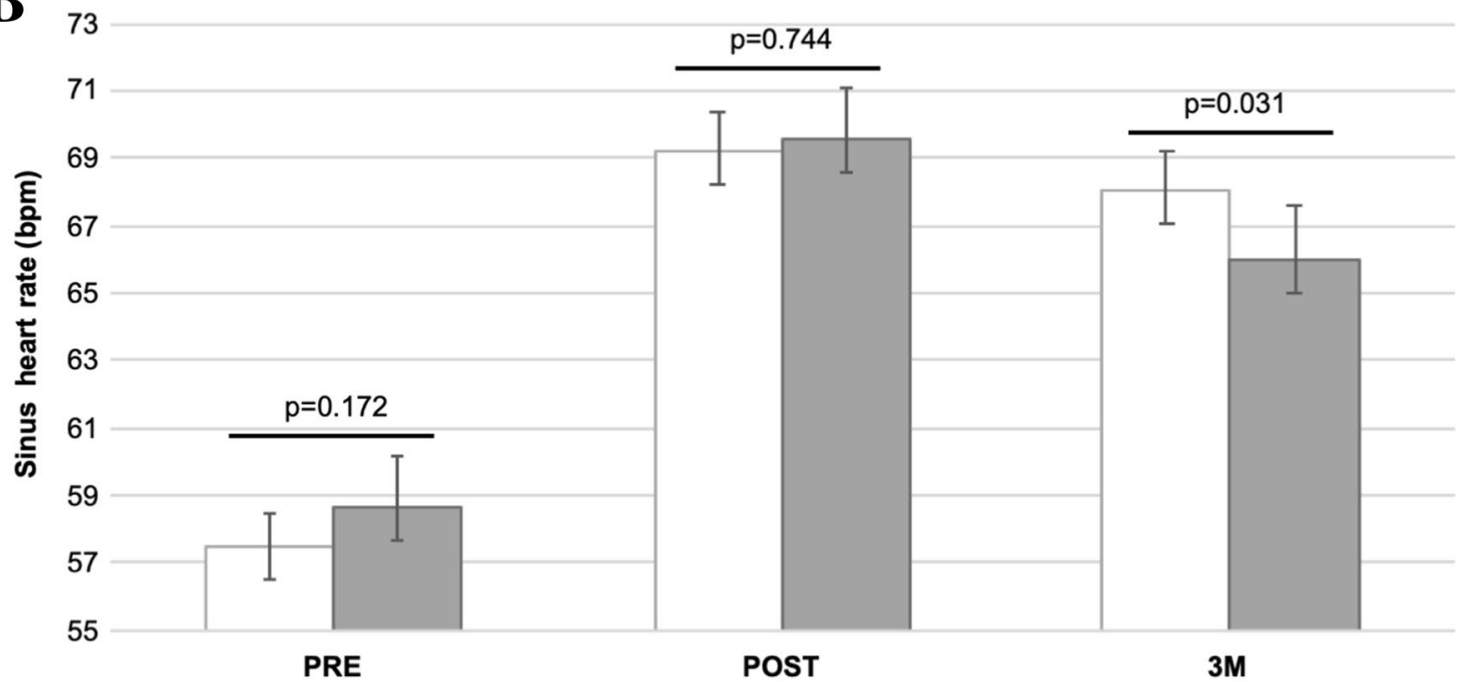

Fig. 1 a Mean sinus heart rate (with 95\% confidence interval) of the total study population at PRE, POST and $3 \mathrm{M}$. b Mean sinus heart rate (with 95\% confidence interval) at PRE, POST and $3 \mathrm{M}$

\section{Consistency analysis}

To investigate whether the observed findings are independent of antiarrhythmic drug effects, we performed a consistency analysis only considering patients without any treatment of beta-blocker or other antiarrhythmic drugs $(n=79)$. In this patient cohort, the mean resting sinus heart at PRE (59.2 bpm at (95\% CI 56.9-61.6 bpm) increased by over $10 \mathrm{bpm}$ to POST (mean $69.6 \mathrm{bpm}$ (95\% CI 67.3-71.9 bpm); $p<0.001)$ and remained high also at $3 \mathrm{M}$ [mean $69.4 \mathrm{bpm}(95 \% \mathrm{CI} 66.9-72.0 \mathrm{bpm})$ ] compared to PRE $(p<0.001)$. (Figure 4 , supplementary). Of these patients, 62 patients $(78.5 \%)$ remained in patients without (white bars) and with (grey bars) recurrence. * $p<0.001$ as compared to PRE

free from recurrences and 17 patients $(21.5 \%)$ developed recurrences.

We further analyzed the heart rate change and the corresponding probability of recurrence. The relation between sinus heart rate change (PRE to $3 \mathrm{M}$ ) and the probability of recurrence [HR 0.86 (95\% CI 0.65-1.15); $p=0.306$ ] as well as the risk increase according to the sinus heart rate change cut-off of $11 \mathrm{bpm}$ [HR 1.80 (95\% CI 0.67-4.88), $p=0.246$ (Figure 5, supplementary) were similar compared to the primary analysis. However, they lacked statistical significance most likely due to the small sample size and number of events. 
Fig. 2 Sinus heart rate change (PRE to $3 \mathrm{M}$ ) with a corresponding probability of recurrence (with $95 \%$ confidence interval)

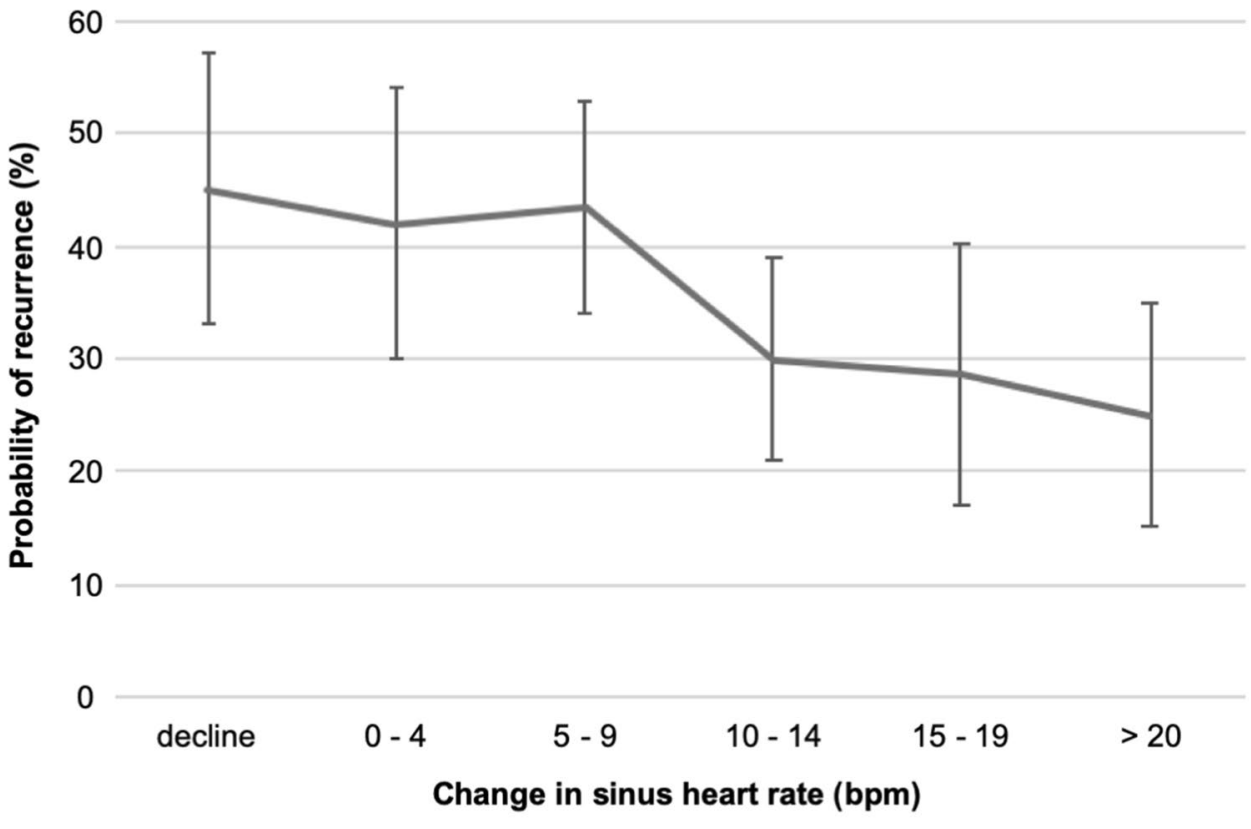

\begin{tabular}{|c|c|c|c|}
\hline Variable & $\begin{array}{l}\text { Sinus heart rate } \\
\text { change }<11 \mathrm{bpm} \text { (PRE to } \\
3 \mathrm{M})(n=266)\end{array}$ & $\begin{array}{l}\text { Sinus heart rate } \\
\text { change }>=11 \mathrm{bpm}(\mathrm{PRE} \text { to } \\
3 \mathrm{M})(n=216)\end{array}$ & $p$ value \\
\hline Beta-blocker at PRE, $n(\%)$ & $170(63.9)$ & $136(63.0)$ & 0.850 \\
\hline Other AADs at PRE & & & 0.408 \\
\hline Dronedarone, $n(\%)$ & $38(14.3)$ & $22(10.2)$ & \\
\hline Flecainid, $n(\%)$ & $26(9.8)$ & $30(13.9)$ & \\
\hline Sotalol, $n(\%)$ & $23(8.6)$ & $20(9.3)$ & \\
\hline Amiodarone, $n(\%)$ & $16(6.0)$ & $8(3.7)$ & \\
\hline Disopyramid, $n(\%)$ & $5(1.9)$ & $3(1.4)$ & \\
\hline Propafenon, $n(\%)$ & $0(0.0)$ & $1(0.5)$ & \\
\hline Beta-blocker at $3 \mathrm{M}, n(\%)$ & $176(66.2)$ & $126(58.3)$ & 0.088 \\
\hline Other AADs at $3 \mathrm{M}$ & & & 0.093 \\
\hline Dronedarone, $n(\%)$ & $19(7.1)$ & $8(3.7)$ & \\
\hline Flecainid, $n(\%)$ & $11(4.1)$ & $8(3.7)$ & \\
\hline Sotalol, $n(\%)$ & $14(5.3)$ & $7(3.2)$ & \\
\hline Amiodarone, $n(\%)$ & $11(4.1)$ & $2(0.9)$ & \\
\hline Disopyramid, $n(\%)$ & $1(0.4)$ & $1(0.5)$ & \\
\hline Propafenon, $n(\%)$ & $0(0.0)$ & $0(0.0)$ & \\
\hline Time of RF energy delivery (sec) & $2710.2 \pm 979.1$ & $2634.2 \pm 906.1$ & 0.446 \\
\hline Procedure time $(\min )$ & $174.4 \pm 50.8$ & $168.4 \pm 49.9$ & 0.145 \\
\hline Fluoroscopy time (min) & $15.3 \pm 8.7$ & $15.9 \pm 10.4$ & 0.826 \\
\hline
\end{tabular}

$A A D$ antiarrhythmic drug, $R F$ radiofrequency
Table 2 Treatment with beta-blocker and other antiarrhythmic drugs as well as procedural characteristics in patients with a sinus heart rate change $<11 \mathrm{bpm}$ and $>=11 \mathrm{bpm}(\mathrm{PRE}$ to $3 \mathrm{M})$

\section{Discussion}

In this study of patients undergoing a first-time PVI procedure, we found that the mean resting heart rate significantly increased at POST and $3 \mathrm{M}$ compared to PRE.
However, only at $3 \mathrm{M}$, there was a significant difference in mean heart rate being lower in patients with compared to patients without recurrences. In this regard, patients with a heart rate change $<11 \mathrm{bpm}$ (PRE to $3 \mathrm{M}$ ) had a significantly higher risk of recurrences compared to the remaining patients. As an alternative marker, a heart 


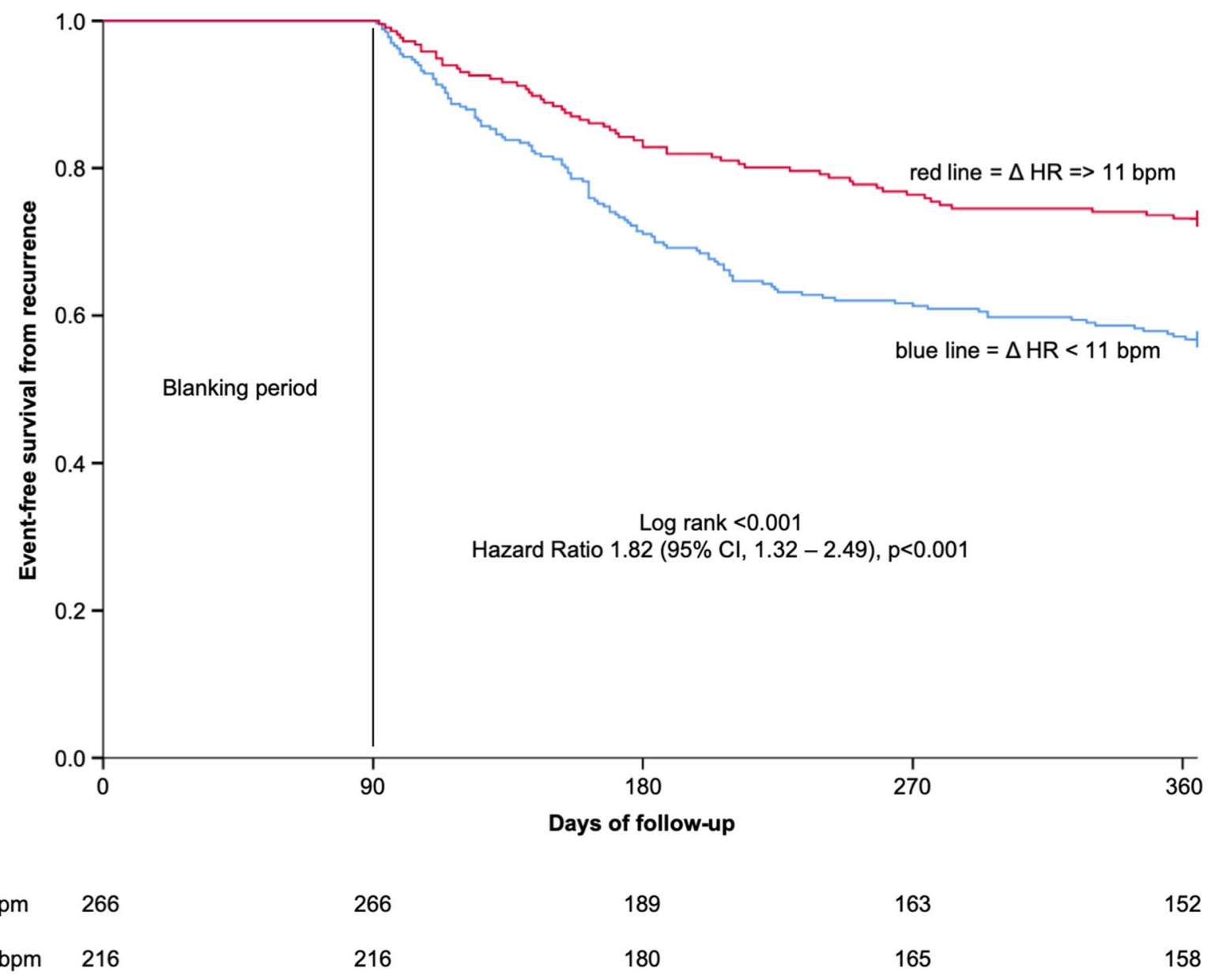

Fig. 3 Kaplan-Meier analysis of event-free survival from recurrence in patients with a sinus heart rate change $<11 \mathrm{bpm}$ compared to $>=11 \mathrm{bpm}$ (PRE to $3 \mathrm{M}$ ) after a one-year follow-up

Table 3 Patients divided into quartiles regarding their sinus heart rate at $3 \mathrm{M}$ and their risk of recurrence development

\begin{tabular}{llll}
\hline $3 \mathrm{M}$ & Hazard ratio & $95 \% \mathrm{CI}$ & $p$ value \\
\hline $\begin{array}{l}\text { 1st quartile: heart rate } \\
\text { 43-59 bpm }\end{array}$ & 1.59 & $1.05-2.38$ & 0.027 \\
$\begin{array}{l}\text { 2nd quartile: heart rate } \\
\text { 60-66 bpm }\end{array}$ & 1.02 & $0.66-1.58$ & 0.938 \\
$\begin{array}{l}\text { 3rd quartile: heart rate } \\
\text { 67-72 bpm }\end{array}$ & 0.88 & $0.56-1.39$ & 0.588 \\
$\begin{array}{l}\text { 4th quartile: heart rate } \\
\text { 73-102 bpm }\end{array}$ & reference & - & - \\
\hline
\end{tabular}

CI confidence interval

rate $<60 \mathrm{bpm}$ at $3 \mathrm{M}$ was associated with an unfavorable outcome in terms of recurrences. Both variables remained independently associated with multivariable analysis.

Our study confirms the significant impact of PVI on cardiac autonomic function with a mean heart rate increase by over $10 \mathrm{bpm}$ at POST which is in line with previously published results [5, 7-9]. This effect is suggested to be induced by parasympathetic denervation owing to PVI ablation $[6,7]$ which is known to influence the sinus rate, the atrial refractory period and atrioventricular conduction [14]. Other contributing factors may be postoperative stress and pain as well as increased fluid load associated with the use of irrigated ablation catheters.

Interestingly, at $3 \mathrm{M}$ the mean heart rate was lower among patients with recurrent atrial fibrillation compared to those without while we did not observe any difference in mean heart rate at PRE or POST. This is in contrast to published results, where this difference in mean heart rate among patients with and without recurrence was already observed directly post-ablation [8]. While the effect of parasympathetic denervation of PVI might be similar directly postablation provided that same ablation techniques have been applied to all patients, lesion maturation with potential restitution during the first weeks or months post-ablation might modify the initially successful impact of parasympathetic denervation. Hence, the discriminatory effect of persistently 


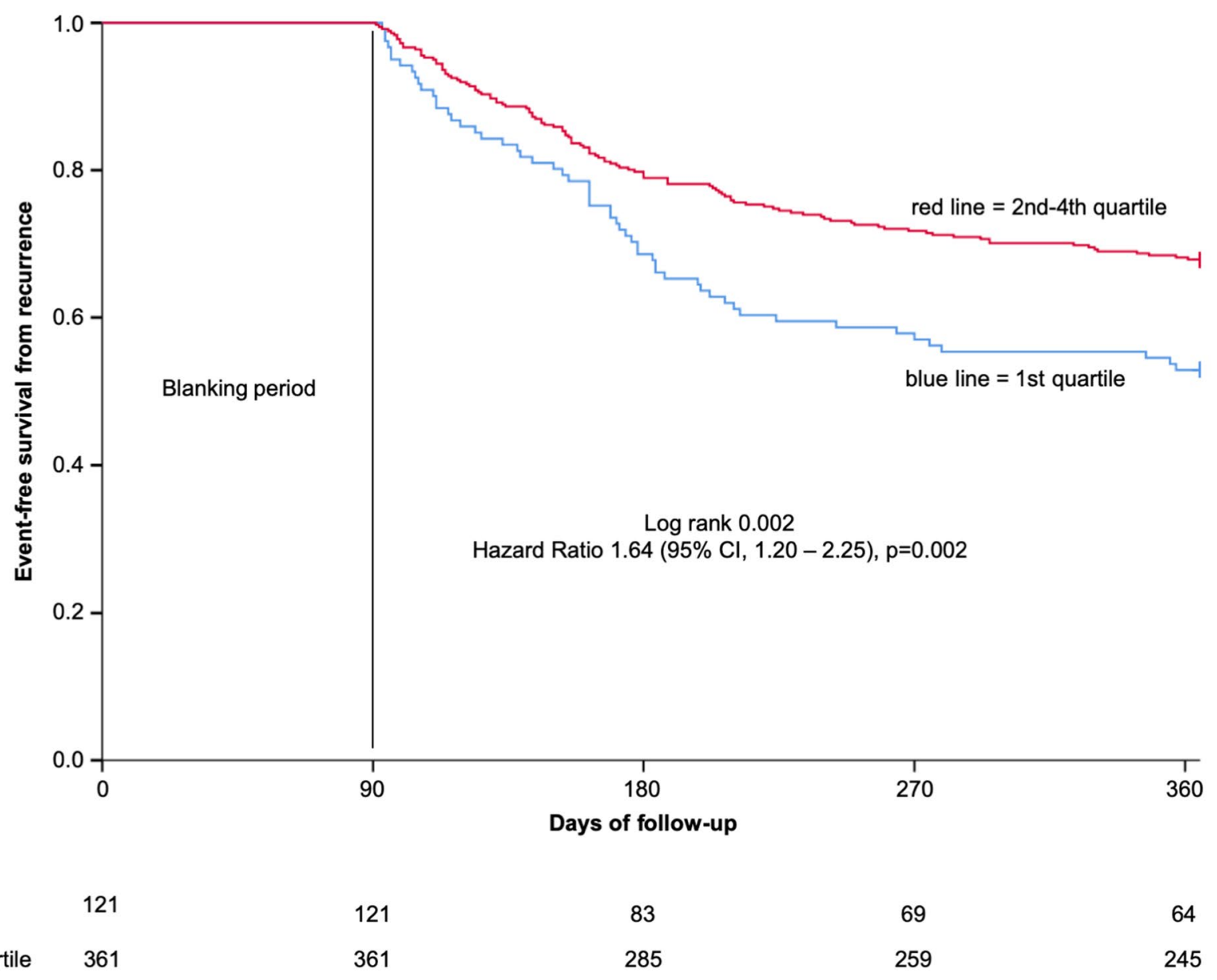

Fig. 4 Kaplan-Meier analysis of event-free survival from recurrence in patients within the 1st quartile compared to 2nd-4th quartile at $3 \mathrm{M}$ after a one-year follow-up

effective parasympathetic denervation might rather be seen later i.e. after 1 month [9] or three months post-ablation as performed in our study.

Patients should be well-informed about the likelihood of an increased heart rate post-PVI since a heart rate increase post-ablation was observed in over $80 \%$ of the patients in our study. However, while an increased heart rate post-ablation seems to be protective with respect to recurrences, it has also been connected to adverse cardiovascular outcomes in patients with but also without cardiovascular risk factors [15-18]. In this context, the extent but also the duration of an elevated heart rate might play an important role. Interestingly, in a study of Pappone et al. changes in heart rate returned to pre-ablation levels at six months [7]. In another study of Nilsson et al., however, heart rate increases postablation persisted during the total follow-up period of 12 months (mean heart rate $70 \mathrm{bpm}$ at 12 months compared to $58 \mathrm{bpm}$ pre-ablation) [9]. Hence, those with persistently elevated heart rates and cardiovascular risk factors might benefit from a more intense beta-blocker therapy.
Treatment with beta-blocker as well as other AADs can modulate the sinus heart rate and, thus, are potential confounders for this study. However, the treatments with betablocker and other ADDs were similar in the analyzed patient groups without statistically significant differences (heart rate change $<11$ bpm vs. $>=11 \mathrm{bpm}$ and 1 st quartile vs. 2 nd -4 th quartile at $3 \mathrm{M}$, respectively). Moreover, the results from the consistency analysis indicate that the observed association between heart rate change and late recurrences are independent of the use of beta-blocker or other AADs.

According to our data, a heart rate change $<11 \mathrm{bpm}$ (PRE to $3 \mathrm{M}$ ) at $3 \mathrm{M}$ is linked to an unfavorable outcome in terms of recurrences during one-year post-PVI. As an alternative parameter, patients with a heart rate $<60 \mathrm{bpm}$ at $3 \mathrm{M}$ are at higher risk for recurrences. This alternative marker might be relevant especially in settings where a PRE ECG is not available. Both parameters are clinically easily applicable tools which aid in identifying patients at high risk for recurrences benefitting from close monitoring. However, a combination with other ECG based markers is to be proven. 
Table 4 Treatment with beta-blocker and other antiarrhythmic drugs as well as procedural characteristics in patients of the 1 st sinus heart rate quartile and 2 nd -4 th sinus heart rate quartile at $3 \mathrm{M}$

\begin{tabular}{|c|c|c|c|}
\hline Variable & $\begin{array}{l}\text { Sinus heart rate 1st quar- } \\
\text { tile }(3 \mathrm{M})(n=121)\end{array}$ & $\begin{array}{l}\text { Sinus heart rate 2nd-4th } \\
\text { quartile }(3 \mathrm{M})(n=361)\end{array}$ & $p$ value \\
\hline Beta-blocker at PRE, $n(\%)$ & $76(62.8)$ & $230(62.7)$ & 0.913 \\
\hline Other AADs at PRE & & & 0.910 \\
\hline Dronedarone, $n(\%)$ & $14(11.6)$ & $46(12.7)$ & \\
\hline Flecainid, $n(\%)$ & $16(13.2)$ & $40(11.1)$ & \\
\hline Sotalol, $n(\%)$ & $12(9.9)$ & $31(8.6)$ & \\
\hline Amiodarone, $n(\%)$ & $7(5.8)$ & $17(4.7)$ & \\
\hline Disopyramid, $n(\%)$ & $3(2.5)$ & $5(1.4)$ & \\
\hline Propafenon, $n(\%)$ & $0(0.0)$ & $1(0.3)$ & \\
\hline Beta-blocker at $3 \mathrm{M}, n(\%)$ & $81(66.9)$ & $221(61.2)$ & 0.279 \\
\hline Other AADs at $3 \mathrm{M}$ & & & 0.126 \\
\hline Dronedarone, $n(\%)$ & $7(5.8)$ & $20(5.5)$ & \\
\hline Flecainid, $n(\%)$ & $9(7.4)$ & $10(2.8)$ & \\
\hline Sotalol, $n(\%)$ & $7(5.8)$ & $14(3.9)$ & \\
\hline Amiodarone, $n(\%)$ & $5(4.1)$ & $8(2.2)$ & \\
\hline Disopyramid, $n(\%)$ & $1(0.8)$ & $1(0.3)$ & \\
\hline Propafenon, $n(\%)$ & $0(0.0)$ & $0(0.0)$ & \\
\hline Time of RF energy delivery (sec) & $2599.3 \pm 910.0$ & $2701.3 \pm 958.3$ & 0.273 \\
\hline Procedure time $(\min )$ & $173.8 \pm 49.0$ & $171.0 \pm 51.0$ & 0.586 \\
\hline Fluoroscopy time (min) & $15.7 \pm 8.7$ & $15.5 \pm 9.7$ & 0.972 \\
\hline
\end{tabular}

$A A D$ antiarrhythmic drug, $R F$ radiofrequency

\section{Limitations}

This is a registry-based cohort study. Moreover, as all data have been collected at a single electrophysiology center with local routines for ablation procedure, results may differ from other centres. Only about a fourth of the screened patients were included in the final analysis which could have led to a potential selection bias. All ablation procedures were performed applying radiofrequency energy and our results may not be applicable to other forms of energy delivery such as cryoablation or more complex ablation techniques. Patients were only selected when sinus rhythm was present at PRE, POST and $3 \mathrm{M}$. Therefore, we cannot firmly conclude on the ablation effect on heart rate in those with ongoing atrial fibrillation at PRE, POST and/or $3 \mathrm{M}$. Since follow-up postablation did not include intensive monitoring by transtelephonic monitoring or implantable loop recorder it is possible that asymptomatic recurrences may have been missed.

\section{Conclusion}

Our study confirms the impact of PVI on cardiac autonomic function with a significant sinus heart rate increase postablation. Patients with a sinus heart rate change $<11 \mathrm{bpm}$ (PRE to $3 \mathrm{M}$ ) are at higher risk for recurrences during oneyear post-PVI. Hence, an extra-careful follow-up of these patients is advisable.

\section{Data availability statement}

The data underlying this article cannot be shared publicly due to the privacy of individuals that were investigated in the study. The data will be shared on reasonable request to the corresponding author provided that this in accordance with the institutional ethical guidelines as well as regulation and legislation.

Funding Open access funding provided by Karolinska Institute. This project was supported by the Deutsche Forschungsgemeinschaft (OL $605 / 1-1)$ to $\mathrm{G}$. O.

\section{Compliance with ethical standards}

Conflicts of interest M. J.-U. is a consultant for Medtronic and Johnson and Johnson and has received research grants from Medtronic. F. B. is a consultant for Medtronic and Biotronik and has received speaker fees from Biotronik, Boston Scientific, Abbott, Pfizer and Orion. For the remaining authors, no conflicts of interest are declared.

Ethical approval All data collection was approved by the regional ethics committee and patient data were collected in accordance with the institutional ethics guidelines.

Open Access This article is licensed under a Creative Commons Attribution 4.0 International License, which permits use, sharing, adaptation, distribution and reproduction in any medium or format, as long as you give appropriate credit to the original author(s) and the source, provide a link to the Creative Commons licence, and indicate if changes were made. The images or other third party material in this article are 
included in the article's Creative Commons licence, unless indicated otherwise in a credit line to the material. If material is not included in the article's Creative Commons licence and your intended use is not permitted by statutory regulation or exceeds the permitted use, you will need to obtain permission directly from the copyright holder. To view a copy of this licence, visit http://creativecommons.org/licenses/by/4.0/.

\section{References}

1. Chugh SS, Havmoeller R, Narayanan K, Singh D, Rienstra M, Benjamin EJ, Gillum RF, Kim YH, McAnulty JH Jr, Zheng ZJ, Forouzanfar MH, Naghavi M, Mensah GA, Ezzati M, Murray CJ (2014) Worldwide epidemiology of atrial fibrillation: a global burden of disease 2010 study. Circulation 129(8):837-847. https ://doi.org/10.1161/CIRCULATIONAHA.113.005119

2. Calkins H, Hindricks G, Cappato R, Kim YH, Saad EB, Aguinaga L, Akar JG, Badhwar V, Brugada J, Camm J, Chen PS, Chen SA, Chung MK, Nielsen JC, Curtis AB, Davies DW, Day JD, d'Avila A, de Groot N, Di Biase L, Duytschaever M, Edgerton JR, Ellenbogen KA, Ellinor PT, Ernst S, Fenelon G, Gerstenfeld EP, Haines DE, Haissaguerre M, Helm RH, Hylek E, Jackman WM, Jalife J, Kalman JM, Kautzner J, Kottkamp H, Kuck KH, Kumagai K, Lee R, Lewalter T, Lindsay BD, Macle L, Mansour M, Marchlinski FE, Michaud GF, Nakagawa H, Natale A, Nattel S, Okumura K, Packer D, Pokushalov E, Reynolds MR, Sanders P, Scanavacca M, Schilling R, Tondo C, Tsao HM, Verma A, Wilber DJ, Yamane T (2017) 2017 HRS/EHRA/ECAS/APHRS/ SOLAECE expert consensus statement on catheter and surgical ablation of atrial fibrillation. Heart Rhythm 14(10):e275-e444. https://doi.org/10.1016/j.hrthm.2017.05.012

3. Chen PS, Chen LS, Fishbein MC, Lin SF, Nattel S (2014) Role of the autonomic nervous system in atrial fibrillation: pathophysiology and therapy. Circ Res 114(9):1500-1515. https://doi. org/10.1161/CIRCRESAHA.114.303772

4. Wu J, Fan X, Yang H, Yan L, Xu X, Duan H, Wang S, Chu Y (2018) Usefulness of a low resting heart rate to predict recurrence of atrial fibrillation after catheter ablation in people $>/=65$ years of age. Am J Cardiol 122(1):97-101. https://doi.org/10.1016/j. amjcard.2018.03.025

5. Wagner L, Darche FF, Thomas D, Lugenbiel P, Xynogalos P, Seide S, Scholz EP, Katus HA, Schweizer PA (2020) Cryoballoon pulmonary vein isolation-mediated rise of sinus rate in patients with paroxysmal atrial fibrillation. Clin Res Cardiol. https://doi. org/10.1007/s00392-020-01659-0

6. Hamdan MH, Page RL, Wasmund SL, Sheehan CJ, Zagrodzky JD, Ramaswamy K, Joglar JA, Adamson MM, Barron BA, Smith ML (2000) Selective parasympathetic denervation following posteroseptal ablation for either atrioventricular nodal reentrant tachycardia or accessory pathways. Am J Cardiol 85(7):875-878. https://doi.org/10.1016/s0002-9149(99)00885-1

7. Pappone C, Santinelli V, Manguso F, Vicedomini G, Gugliotta F, Augello G, Mazzone P, Tortoriello V, Landoni G, Zangrillo A,
Lang C, Tomita T, Mesas C, Mastella E, Alfieri O (2004) Pulmonary vein denervation enhances long-term benefit after circumferential ablation for paroxysmal atrial fibrillation. Circulation 109(3):327-334. https://doi.org/10.1161/01.CIR.0000112641 $.16340 . \mathrm{C} 7$

8. Goff ZD, Laczay B, Yenokyan G, Sivasambu B, Sinha SK, Marine JE, Ashikaga H, Berger RD, Spragg DD, Calkins H (2019) Heart rate increase after pulmonary vein isolation predicts freedom from atrial fibrillation at 1 year. J Cardiovasc Electrophysiol. https://doi. org $/ 10.1111 /$ jce. 14257

9. Nilsson B, Chen X, Pehrson S, Hilden J, Svendsen JH (2005) Increased resting heart rate following radiofrequency catheter ablation for atrial fibrillation. Europace 7(5):415-420. https:// doi.org/10.1016/j.eupc.2005.04.006

10. Yu HT, Kim TH, Uhm JS, Kim JY, Joung B, Lee MH, Pak HN (2017) Prognosis of high sinus heart rate after catheter ablation for atrial fibrillation. Europace 19(7):1132-1139. https://doi. org/10.1093/europace/euw142

11. Kirchhof P, Benussi S, Kotecha D, Ahlsson A, Atar D, Casadei B, Castella M, Diener HC, Heidbuchel H, Hendriks J, Hindricks G, Manolis AS, Oldgren J, Popescu BA, Schotten U, Van Putte B, Vardas P, Group ESCSD (2016) 2016 ESC Guidelines for the management of atrial fibrillation developed in collaboration with EACTS. Eur Heart J 37(38):2893-2962. https://doi.org/10.1093/ eurheartj/ehw210

12. Akerstrom F, Bastani H, Insulander P, Schwieler J, Arias MA, Jensen-Urstad M (2014) Comparison of regular atrial tachycardia incidence after circumferential radiofrequency versus cryoballoon pulmonary vein isolation in real-life practice. J Cardiovasc Electrophysiol 25(9):948-952. https://doi.org/10.1111/jce.12423

13. Hothorn T, Lausen B (2003) On the exact distribution of maximally selected rank statistics. Comput Stat Data Anal 43(2):121-137

14. Schauerte P, Scherlag BJ, Pitha J, Scherlag MA, Reynolds D, Lazzara R, Jackman WM (2000) Catheter ablation of cardiac autonomic nerves for prevention of vagal atrial fibrillation. Circulation 102(22):2774-2780. https://doi.org/10.1161/01.cir.102.22.2774

15. Bohm M, Swedberg K, Komajda M, Borer JS, Ford I, DubostBrama A, Lerebours G, Tavazzi L, Investigators S (2010) Heart rate as a risk factor in chronic heart failure (SHIFT): the association between heart rate and outcomes in a randomised placebo-controlled trial. Lancet 376(9744):886-894. https://doi. org/10.1016/S0140-6736(10)61259-7

16. Diaz A, Bourassa MG, Guertin MC, Tardif JC (2005) Long-term prognostic value of resting heart rate in patients with suspected or proven coronary artery disease. Eur Heart J 26(10):967-974. https://doi.org/10.1093/eurheartj/ehi190

17. Gillman MW, Kannel WB, Belanger A, D’Agostino RB (1993) Influence of heart rate on mortality among persons with hypertension: the Framingham study. Am Heart J 125(4):1148-1154. https ://doi.org/10.1016/0002-8703(93)90128-v

18. Kannel WB, Kannel C, Paffenbarger RS Jr, Cupples LA (1987) Heart rate and cardiovascular mortality: the Framingham study. Am Heart J 113(6):1489-1494. https://doi.org/10.1016/00028703(87)90666-1 